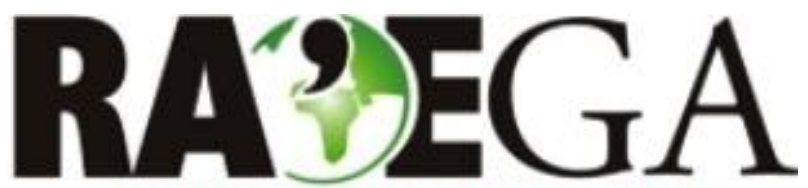

O ESPAÇO GEOGRÁFICO EM ANÁLISE

\title{
ESPACIALIZAÇÃO DO ÍNDICE DE CAMINHABILIDADE (IC) COMO FERRAMENTA DE PLANEJAMENTO PARA MOBILIDADE URBANA DOS BAIRROS CENTRO E BADENFURT EM BLUMENAU (SC)
}

\section{RATING SYSTEM FOR WALKABILITY (IC) AS PLANNING TOOL FOR URBAN MOBILITY IN DOWNTOWN AND BADENFURT NEIGHBORHOODS IN BLUMENAU (SC)}

\author{
Gustavo Antonio Piazza ${ }^{1}$, Rafaela Vieira ${ }^{2}$
}

\section{RESUMO}

Problemas de mobilidade urbana são correntes na atualidade. Na cidade Blumenau (SC), no sul do Brasil, o tema tem ganhado atenção após aprovação da Lei Federal no. 12.587/2012, que institui a Política Nacional de Mobilidade Urbana. Diversos tipos de estudos e diagnósticos têm sido realizados no sentido de mensurar e propor melhorias sobre o deslocamento de bens e pessoas, dando-se destaque para os modos coletivos e não motorizados de transporte, incluindo neste caso o caminhar. Para entender a qualidade das calçadas são utilizados índices de aferição, como o Índice de Caminhabilidade (IC). O objetivo deste estudo foi identificar e mapear o IC de dois bairros de Blumenau, em Santa Catarina. Neste estudo foi utilizado um Sistema de Informação Geográfica (SIG) para espacializar O IC nos bairros, que possuem deficiências no sistema de mobilidade. A pesquisa tem caráter quantitativo, do tipo explicativa e estruturou-se em três etapas: coleta de dados em campo, mapeamento das informações e análise e discussão dos resultados. A espacialização das informações foi executada com o software ArcGIS 10.3. Encontrou-se uma média superior de IC no bairro do Centro em relação ao Badenfurt, tanto em número como em extensão de trechos. A ferramenta proposta demonstrou ser adequada, podendo ser utilizada como suporte no processo de tomada de decisão relativo ao planejamento do espaço geográfico.

PALAVRAS-CHAVE: Mobilidade; Acessibilidade; Sistema de Informações Geográficas (SIG); planejamento ambiental e Urbano

\begin{abstract}
Urban mobility problems are common in many countries. In Blumenau (Santa Catarina State), Southern Brazil, the subject has gained attention after the Federal Law no. 12.587/2012, which establishes the National Urban Mobility Policy. In the meantime, various types of studies have been carried out to measure and improve human and cargo transportation, such as collective and non-motorized types of transportation, including walk. To understand the quality of this type of transport is recommend the use of indexes, such as the Walk Index (called here IC). This study aim of to identify and map the IC in two neighborhoods, in Blumenau, State of Santa Catarina, Southern Brazil. In this study, a Geographic Information System (GIS) was used to spatialize the IC in the studied neighborhoods which has deficiencies in the mobility system. Following quantitative approach, the research was structured in three stages: field data collection, spatial planning and results. Thematic maps were performed through ArcGIS 10.3 software. The Center presented the highest IC over Badenfurt neighborhood, in both number and extension of paths. The proposed tool proved to be adequate and can be used as support in the decision-making process related to the geographic space.
\end{abstract}

KEY-WORDS: mobility; accessibility; Geographic Information System (GIS); environmental and urban planning.

Recebido em: 18/12/2015

Aceito em: 05/07/2017

\footnotetext{
${ }^{1}$ Fundação Universidade Regional de Blumenau, Blumenau/SC e-mail: guinuzaum@gmail.com

${ }^{2}$ Fundação Universidade Regional de Blumenau, Blumenau/SC, e-mail: arquitetura.rafaela@gmail.com
} 


\section{ESPACIALIZAÇÃO DO ÍNDICE DE CAMINHABILIDADE (IC) COMO FERRAMENTA DE PLANEJAMENTO NA MOBILIDADE URBANA DOS BAIRROS CENTRO E BADENFURT EM BLUMENAU (SC)}

\section{INTRODUÇÃO}

A Lei Federal no. 12.587 de 03/01/2012, que institui a Política Nacional de Mobilidade Urbana (PNMU), define mobilidade como a condição em que se realizam os deslocamentos de pessoas e cargas na cidade. Em seu artigo 3으, a referida lei explicita que o Sistema Nacional de Mobilidade Urbana (SNMU) é composto pelo conjunto organizado e coordenado dos modos de transporte, serviços e infraestruturas que garantem deslocamentos municipais (BRASIL, 2012). Dentre os modos de transporte pode-se citar o pedonal, bicicleta, tração animal, motocicleta, automóveis, ônibus, bonde, embarcação e outros. O sistema de mobilidade dever ter uma abordagem multimodal e integrada, conectando distintas tecnologias, serviços e infraestruturas de forma complementar. Porém, esta situação não é observada, principalmente em países em desenvolvimento. Segundo Rech (2004), mais de $80 \%$ da população urbana brasileira utiliza basicamente o veículo automotor (individual e coletivo) como forma de transporte. O resultado dessa estatística pode ser visualizado em problemas de mobilidade que são recorrentes em várias cidades brasileiras, como congestionamentos, acidentes e baixa qualidade nos outros modais. Somado a isso existe também a depreciação da qualidade atmosférica, já que veículos são responsáveis por $20 \%$ da emissão dos gases que provocam o efeito estufa (STEINER, 2009).

A utilização do veículo automotor tem relação com a configuração das cidades. Para Vieira e Morastoni (2013), em sua maioria, a configuração dispersa das áreas urbanas está diretamente relacionada à evolução do transporte automotivo, tendo em vista que ele exerce influência na localização, tamanho e forma das cidades, assim como nos hábitos de sua população. Diante dessa realidade, o caminhar se destaca com vantagens ambientais, econômicas e sociais, afinal, somos pedestres em algum momento do dia e o caminhar é a forma de locomoção da maior parte das pessoas (VIEIRA, PACKER e MENESES, 2016). De acordo com Barton e Pretty (2010) e Szeremeta e Zannin (2013), cinco minutos de caminhada é suficiente para melhorar a saúde mental, com benefícios para o humor e autoestima. Para tanto, os passeios públicos devem possuir características que possibilitem o acesso universal e adequado ao espaço urbano.

Mas para se incentivar o caminhar, calçadas devem ter um padrão de qualidade, que possibilitem a caminhabilidade (SIEBERT; LORENZINI, 1998). Para Ghidini (2011, p. 22), “[...] a caminhabilidade é uma qualidade do lugar; o caminho que permite ao pedestre uma boa acessibilidade às diferentes partes da cidade [...]" sejam crianças, idosos ou pessoas com deficiência. Portanto, a caminhabilidade é uma das condições que influenciam a mobilidade urbana (BUDAG e VITORINO, 2005). Entretanto, como na maioria das cidades brasileiras, os meios para realização de tais deslocamentos são inexistentes ou, quando existem se encontram inadequados ou em mau estado de conservação, não recebendo a devida atenção tanto por parte do poder público quanto dos proprietários dos lotes. As calçadas são espaços públicos, contudo, na maioria dos códigos de posturas dos municípios, os proprietários são definidos como os responsáveis por sua implantação e manutenção. Desta forma, o poder público passa sucessivamente aos proprietários dos lotes lindeiros a incumbência que Ihe era devida.

Uma forma de mensurar a qualidade dos deslocamentos é o cálculo do índice de Caminhabilidade (IC). Estudos sobre caminhabilidade foram iniciados por Bradshaw (1993) quando comerciantes e donos de imóveis urbanos no Canadá começaram a questionar os impostos tendo em vista a má qualidade das calçadas. Ainda na década de 1990, a metodologia canadense foi adaptada à realidade Blumenauense por Siebert e Lorenzini (1998) e aplicada em alguns bairros da cidade. Experiências semelhantes foram realizadas em outras cidades catarinenses e paranaense, na década de 2000, tendo participado, por exemplo, Itajaí, Camboriú, Itapema e Foz do Iguaçu (BUDAG e VITORINO, 2005; RUTZ, MERINO e 
PRADO, 2007; BUDAG e TRICÁRICO, 2009, VIEIRA

E MORASTONI, 2013; VIEIRA, PEREIRA E MUSSI, 2014; VIEIRA, PACKER e MENESES, 2016).

Para se fazer um diagnóstico relativo ao espaço geográfico, como no caso da qualidade das calçadas, são necessárias etapas de aquisição e processamento de dados. A base dos estudos geográficos é a aquisição de dados em campo, no entanto, sua execução tem sido substituída com a popularização das técnicas computacionais e de obtenção de dados via sensoriamento remoto (aerolevantamento - avião ou drone - ou plataforma orbital - satélite). A aplicação conjunta, no entanto, se faz fundamental em estudos de planejamento urbano. Dados atualizados de campo com sua devida coordenada geográfica são utilizados para representar o espaço geográfico por meio dos Sistemas de Informação Geográfica (SIG). Um SIG consiste do conjunto de dados, equipamentos, plataformas computacionais e pessoas, utilizado para armazenar, analisar e extrair informações georeferrenciadas. Para Silva e Zaidan (2004) e Rocha, Ximenes e Guerra (2015), os SIG são ferramentas fundamentais no planejamento urbano, pois facilitam o tratamento e a atualização dos dados espaciais, como acompanhar de mudanças de espaço e tempo, essenciais na elaboração de políticas públicas voltadas aos municípios.

Partindo da premissa que a cidade é um sistema complexo e dinâmico, cuja infraestrutura urbana encontra-se em constante transformação, este trabalho teve por objetivo identificar e mapear o IC de dois bairros de Blumenau, em Santa Catarina. Foram utilizados dados coletas in loco e um SIG. O artigo encontra-se estruturado em cinco seções: (1) introdução com referências teóricas sobre mobilidade urbana e índice de caminhabilidade; (2) breve histórico da cidade e da mobilidade urbana de Blumenau; (3) o método de coleta e técnica de análise dos dados; (4) resultados e discussões e (5) fechamento com as considerações finais.

\section{HISTÓRICO DA CIDADE E DA MOBILIDADE URBANA DE BLUMENAU (SC)}

Blumenau foi colonizada em meados do século XIX por imigrantes alemães, sendo a área central a primeira a ser colonizada. Segundo Budag (2004), a influência da colonização estrangeira e o processo de colonização por meio da iniciativa privada iniciada pelo Dr. Hermann Bruno Otto Blumenau, delinearam uma forma própria de organização e de ocupação do espaço. Somado a isso, tem-se as condicionantes naturais, cuja geomorfologia é caracterizada por uma topografia acidentada, com encostas que apresentam grande amplitude e inclinação, permeadas por uma complexa rede de drenagem. Tem-se, portanto, uma malha urbana compartimentada por morros e cujas principais vias margeiam rios e ribeirões, visto que a ocupação urbana ocorreu ao longo dos fundos de vale. Devido a isso, a cidade sofre também com problemas recorrentes relacionados a deslizamentos, enchentes e inundações (FRANK; AUMMOND, 2009).

O principal modal de transporte em Blumenau é o veículo automotor individual. No entanto, boa parte da população utiliza o transporte coletivo por veículo automotor, que desde 2011 conta com corredores exclusivos no sistema viário central. Boa parte da população dirige-se diariamente dos bairros mais afastados e de cidades vizinhas até o centro da cidade, o que causa constantes congestionamentos no sistema de mobilidade municipal.

A cidade contou com seu primeiro Código de Posturas em 1883, sendo seu primeiro regulamento construtivo, o Código de Construções, aprovado em 1939. De acordo com Siebert (2000), o primeiro Plano Diretor da cidade é de 1977, elaborado por uma equipe externa, de forma tecnocrática, com pouca participação da Prefeitura e limitada participação popular. Este plano foi revisado em 1989 e 1996/1997, passando posteriormente por alterações pontuais. Após a aprovação do Estatuto da Cidade, Lei Federal no. 10.257/2001, o Plano Diretor foi reestruturado em 2006 e conta com uma seção sobre a Política de desenvolvimento 


\section{ESPACIALIZAÇÃO DO ÍNDICE DE CAMINHABILIDADE (IC) COMO FERRAMENTA DE PLANEJAMENTO NA MOBILIDADE URBANA DOS BAIRROS CENTRO E BADENFURT EM BLUMENAU (SC)}

urbano, a qual trata da Política Pública Municipal de Acessibilidade Urbana e do Sistema de Circulação.

Desde 2005, a Lei Complementar no 550/2005 dispõe sobre a construção de passeios públicos ou calçadas no município, tendo sido elaborada uma cartilha para orientação da população. A cartilha para implantação e manutenção das calçadas passou por reformulações em 2012 e 2015. Nesta última reformulação, a prefeitura municipal, por meio da Secretaria de Planejamento Urbano, lançou o Programa Calçada nota 10, cujo objetivo é sensibilizar os proprietários para a melhoria da caminhabilidade, tornando as calçadas acessíveis a todos. Desde 2016, o município de Blumenau está elaborando seu Plano Municipal de Mobilidade Urbana, conforme exigência da Lei Federal no 12.587/2012 (VIEIRA, PACKER e MENESES, 2016).

Tendo em vista o histórico promissor, porém ainda incipiente em termos de mobilidade urbana, é possível afirmar que Blumenau possui problemas em relação à mobilidade urbana, com possibilidades de melhoria no que tange aos veículos automotores e aos não motorizados, sendo estudos e diagnósticos fundamentais no município.

\section{MATERIAIS E MÉTODOS ÁREA DE ESTUDO}

A área de estudo localiza-se no município de Blumenau (Figura 1), na bacia hidrográfica do rio Itajaí-Açú, no estado de Santa
Catarina, sul do Brasil. De acordo com IBGE (2015), Blumenau possui uma população estimada de 338.876 habitantes, distribuídos em uma área territorial de 518,497 km², com uma densidade demográfica $653,57 \mathrm{hab} / \mathrm{km}^{2}$. A área urbana de Blumenau é dividida em 35 bairros de acordo com a Lei Complementar $n^{\circ}$ 489/2004, incluindo 2 distritos (Vila Itoupava e o Grande Garcia).

Neste trabalho, foram analisados o Centro e o bairro periférico do Badenfurt. Os dois bairros possuem características distintas, sendo no Centro concentrada a área de comércio, a maior renda e a maior densidade demográfica (1500-2000 hab/ $\mathrm{km}^{2}$ ). Segundo Budag (2004), a área central de Blumenau constitui-se no espaço de máxima centralidade, com as maiores opções de comércio e prestação de serviços, inclusive públicos. Já o Badenfurt é um bairro limítrofe (divisa com o município de Indaial), periférico, com menor densidade demográfica (500-1000 $\mathrm{hab} / \mathrm{km}^{2}$ ) e população de baixa renda (BLUMENAU, 2005). A população por bairro, de acordo com IBGE 2010, é de 5004 habitantes para o Centro e de 8650 habitantes para o Badenfurt. No entanto, em relação à dimensão, a área de cobertura do bairro Centro possui apenas 2,37 $\mathrm{km}^{2}$ (perfazendo $1 \%$ da área territorial urbana), enquanto o bairro Bandenfurt possui $11,54 \mathrm{~km}^{2}$ (correspondendo a 5,6\% da área territorial urbana). 


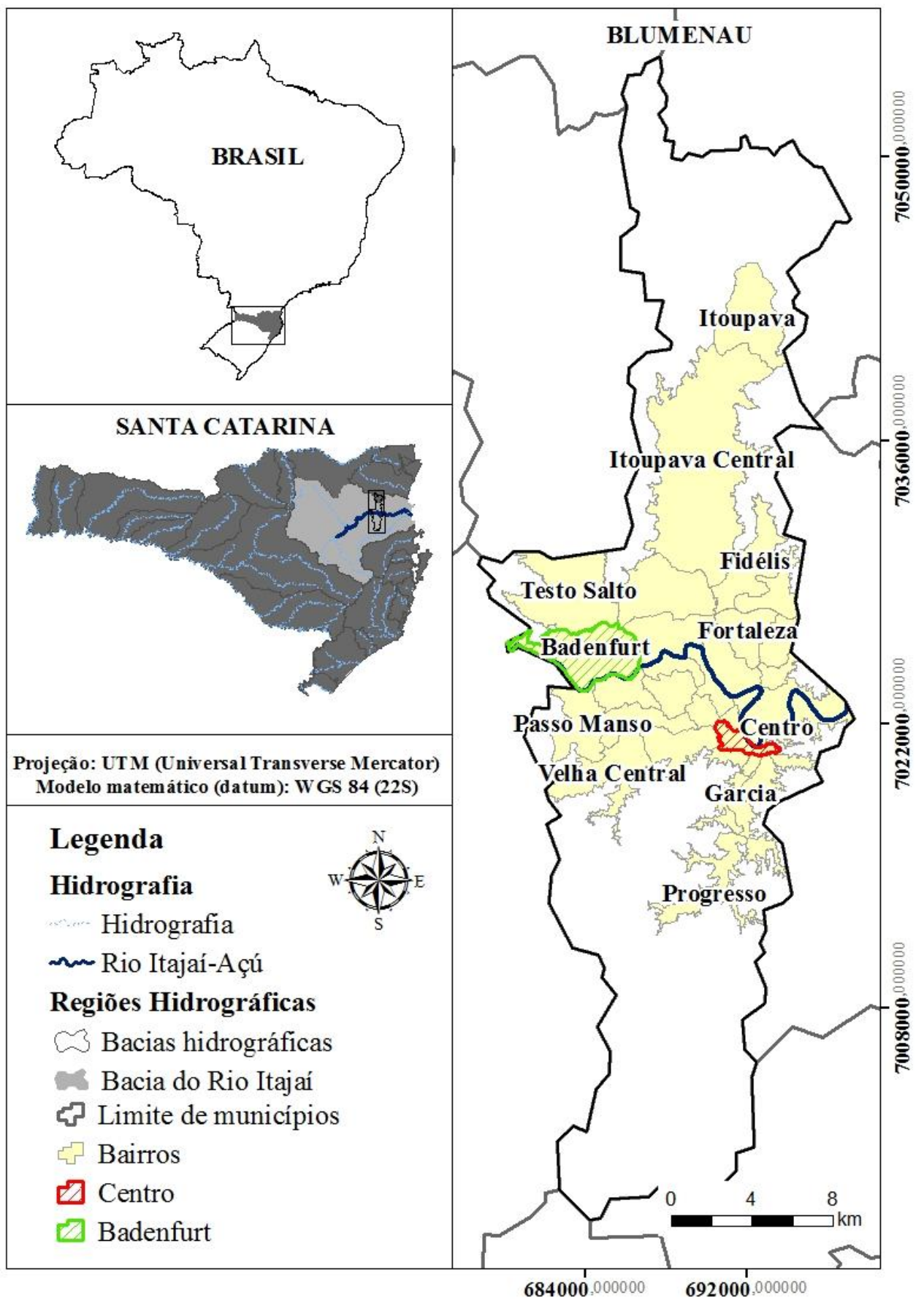

Figura 01 - Localização da área de estudo, município de Blumenau (SC).

\section{LEVANTAMENTO EM CAMPO E CÁLCULO DO IC}

O levantamento das informações consistiu de duas ações: coleta dos dados de campo e cálculo e espacialização do IC. Antes de ir a campo, no entanto, uma etapa preliminar de planejamento das atividades foi realizada sobre o mapa cadastral do município. Bases cartográficas georeferenciadas (curvas de nível, cursos de água, limite de municípios, entre outros) foram obtidas na Prefeitura Municipal de Blumenau, pela Secretaria de Planejamento Urbano, junto à Diretoria de Cartografia, Cadastro Multifinalitário e Informações. Foi utilizada uma planilha baseada na metodologia canadense de avaliação do Índice de Caminhabilidade, que leva em conta dez (10) variáveis (BRADSHAW, 1993; SIEBERT; LORENZINI, 1998) (Quadro 1). Além das 10 


\section{ESPACIALIZAÇÃO DO ÍNDICE DE CAMINHABILIDADE (IC) COMO FERRAMENTA DE PLANEJAMENTO NA MOBILIDADE URBANA DOS BAIRROS CENTRO E BADENFURT EM BLUMENAU (SC)}

variáveis explicitadas por Siebert e Lorenzini (1998), foram propostas mais seis (06) variáveis adicionais (tipo de pavimento, rebaixo do meio fio, drenagem, localização, conservação e disposição) (Quadro 1). Mais informações sobre o IC podem ser encontradas em Bradshaw (1993), Siebert e Lorenzini (1998) e Santos (2003). A metodologia de Siebert e Lorenzini (1998) utiliza a versão adaptada à realidade local, tendendo aos fatores de análise quantitativa, eliminando-se ao máximo os fatores de análise qualitativa, em função do seu grau de subjetividade.

Quadro 01 - Dezesseis variáveis avaliadas durante o levantamento em campo nos bairros Centro e Badenfurt - Blumenau (SC).

\begin{tabular}{|c|c|c|c|}
\hline Variáveis & \multicolumn{3}{|c|}{ Opções de avaliação } \\
\hline $\begin{array}{l}\text { 1. Largura da } \\
\text { Calçada }\end{array}$ & $\begin{array}{l}\text { Largura livre superior a } \\
\text { um metro. }\end{array}$ & $\begin{array}{l}\text { Largura livre inferior a um } \\
\text { metro }\end{array}$ & Calçada inexistente \\
\hline $\begin{array}{l}\text { 2. Condição do } \\
\text { piso }\end{array}$ & Piso em boas condições & Piso mal conservado & Piso inexistente \\
\hline 3. Obstáculos & $\begin{array}{l}\text { Calçada livre de } \\
\text { obstáculos ao } \\
\text { deslocamento de } \\
\text { pedestres }\end{array}$ & $\begin{array}{l}\text { Calçada com obstáculos } \\
\text { (árvores, postes, mobiliário } \\
\text { urbano) }\end{array}$ & $\begin{array}{l}\text { Calçada obstruída } \\
\text { (pedestre anda na rua) }\end{array}$ \\
\hline 4. Nivelamento & $\begin{array}{l}\text { Calçada com } \\
\text { declividade mínima (até } \\
2 \% \text { ) }\end{array}$ & $\begin{array}{l}\text { Calçada com declividade } \\
\text { acentuada (acima de } 2 \% \text { ) }\end{array}$ & $\begin{array}{l}\text { Calçada interrompida por } \\
\text { degraus ou rampa }\end{array}$ \\
\hline $\begin{array}{l}\text { 5. Proteção } \\
\text { contra } \\
\text { intempérie }\end{array}$ & $\begin{array}{l}\text { Calçada protegida da } \\
\text { chuva e do sol. }\end{array}$ & $\begin{array}{l}\text { Calçada parcialmente } \\
\text { protegida }\end{array}$ & $\begin{array}{l}\text { Calçada sem sombra ou } \\
\text { proteção contra chuva }\end{array}$ \\
\hline $\begin{array}{l}\text { 6. Mobiliário } \\
\text { Urbano }\end{array}$ & $\begin{array}{l}\text { Calçada dotada de itens } \\
\text { de conforto }\end{array}$ & $\begin{array}{l}\text { Calçada adotada com pelo } \\
\text { menos um item de conforto }\end{array}$ & $\begin{array}{l}\text { Calçada sem mobiliário } \\
\text { urbano }\end{array}$ \\
\hline 7. Iluminação & Calçada bem iluminada & $\begin{array}{l}\text { Calçada parcialmente } \\
\text { iluminada }\end{array}$ & $\begin{array}{l}\text { Calçada sem iluminação } \\
\text { noturna }\end{array}$ \\
\hline 8. Uso lindeiro & $\begin{array}{l}\text { Calçada com uso } \\
\text { lindeiro agradável }\end{array}$ & $\begin{array}{l}\text { Calçada com o uso lindeiro } \\
\text { neutro }\end{array}$ & $\begin{array}{l}\text { Presença de depósito de } \\
\text { resíduos, esgoto a céu } \\
\text { aberto ou qualquer tipo } \\
\text { de descomforto }\end{array}$ \\
\hline 9. Travessia & $\begin{array}{l}\text { Calçada com boa } \\
\text { segurança }\end{array}$ & $\begin{array}{l}\text { Calçada com segurança } \\
\text { razoável }\end{array}$ & $\begin{array}{l}\text { Calçada sem condições } \\
\text { de segurança }\end{array}$ \\
\hline $\begin{array}{l}\text { 10. Ambiente } \\
\text { Psico-Social }\end{array}$ & $\begin{array}{l}\text { Calçada em região } \\
\text { inóspita/perigosa e sem } \\
\text { policiamento }\end{array}$ & $\begin{array}{l}\text { Calçada com média } \\
\text { densidade de pedestres e } \\
\text { sem policiamento }\end{array}$ & $\begin{array}{l}\text { Calçada em região } \\
\text { inóspita/ perigosa e sem } \\
\text { policiamento }\end{array}$ \\
\hline \multicolumn{4}{|c|}{ Variáveis adicionais } \\
\hline $\begin{array}{l}\text { 1. Tipo de } \\
\text { pavimento }\end{array}$ & Concreto Paver & $\begin{array}{ll}\text { Ladrilho } & \text { Lajotas } \\
\text { Hidráulico } & \text { Cerâmicas }\end{array}$ & Não possui \\
\hline $\begin{array}{l}\text { 2. Rebaixo do } \\
\text { meio fio }\end{array}$ & $\begin{array}{l}\text { Existe e não segue } \\
\text { ABNT }\end{array}$ & Não existe & \\
\hline 3. Drenagem & Existe & Não existe & \\
\hline 4. Localização & Início e fim & Início ou fim & \\
\hline 5. Conservação & Boas condições & Más condições & \\
\hline 6. Disposição & Antes do raio de curva & No raio da curva & \\
\hline \multicolumn{4}{|c|}{ Informações gerais } \\
\hline Nome da Rua & Município & Bairro & Trecho \\
\hline
\end{tabular}




\section{ESPACIALIZAÇÃO DO ÍNDICE DE CAMINHABILIDADE (IC) COMO FERRAMENTA DE PLANEJAMENTO NA MOBILIDADE URBANA DOS BAIRROS CENTRO E BADENFURT EM BLUMENAU (SC)}

As variáveis receberam pontuação de um (1), meio $(0,5)$ ou zero (0) pontos, referindose respectivamente, a uma situação de caminhabilidade ótima, moderada ou inadequada ao deslocamento. Todas as informações foram coletadas para cada trecho de calçada, em face a uma quadra, por meio da ficha descritiva de campo e registro fotográfico. As informações, depois de digitalizadas, foram utilizadas no cálculo do IC, indicando a situação das calçadas e caracterizando a prioridade de intervenção (Tabela 1).

Tabela 01 - Índice de Caminhabilidade e prioridade de intervenção

\begin{tabular}{ll}
\hline Índice de caminhabilidade & Prioridade de intervenção \\
\hline 6,00 a 10,00 (Ótima) & Melhorias e aperfeiçoamento \\
4,0 a 5,90 (Moderada) & Intervenção a curto prazo \\
2,0 a 3,9 (Ruim) & Intervenção imediata \\
0 a 1,9 (Inadequada) & Situação crítica \\
\hline
\end{tabular}

Fonte: Santos (2003).

A primeira vez que este índice foi aplicado na cidade de Blumenau, foi em 2005, com auxílio de 17 bolsistas da Universidade Regional de Blumenau (FURB), em todos os bairros de Blumenau avaliando calçadas em critérios que variaram de 0 a 10. (VIEIRA, PACKER e MENESES, 2016). Em 2015, tendo em vista o número limitado de bolsistas e viabilidade da pesquisa, optou-se pela escolha do bairro Centro e Badenfurt, sendo que em 2005 eles apresentaram a melhor $(7,6)$ e a pior $(1,8)$ média de IC, além de constituir-se em áreas consolidadas e em consolidação, respectivamente. As novas coletas de dados de campo foram realizadas durante o ano de 2015.

\section{GEOPROCESSAMENTO}

Todas as etapas de geoprocessamento foram efetuadas com o software ArcGIS 10.3. Foi usado como base o mapa cadastral de ruas fornecido pela Prefeitura de Blumenau, que conta com dados digitais (layers), como: vias, calçadas, cursos de água, infraestrutura urbana, limites de bairros, entre outros, gerado em CAD com escala de 1:5000. Depois de importá-lo para - SIG, os trechos de calçadas (utilizados para cálculos do IC em campo) foram vetorizados de acordo com o mapa cadastral usando a ferramenta trace (contorno). Todas informações foram trabalhadas no datum WGS 1984 para o fuso $22 \mathrm{~S}$, referente ao município de Blumenau. Todos os trechos de ruas receberam um número identificador (ID). Os resultados do IC para cada trecho foram inseridos para dentro dos SIG, já que o SIG possui também possibilidade de inserção de informação tabular (no arquivo .dbf ou database format). O IC de cada trecho foi inserido de forma manual de acordo com o resultado do IC e o ID, usando a tabela de atributos. As classes de IC foram definidas por meio da ferramenta simbology (simbologia), no qual seguiu-se padrão da Tabela 1. Utilizando a ferramenta calculate geometry (calcular a geometria) foi calculada a extensão de cada trecho de calçada. Os mapas foram exportados em formato de figura (.jpg) para apresentação.

\section{RESULTADOS E DISCUSSÃO}

Calçadas no bairro do Centro possuem maior qualidade tanto em número como em extensão de trechos de calçadas em relação ao bairro Badenfurt (Tabela 2), sendo que no Centro $68 \%(134 / 196)$ dos trechos possui IC bom (6-10) e no Badenfurt apenas $17 \%$ (11/65). 


\section{ESPACIALIZAÇÃO DO ÍNDICE DE CAMINHABILIDADE (IC) COMO FERRAMENTA DE PLANEJAMENTO NA MOBILIDADE URBANA DOS BAIRROS CENTRO E BADENFURT EM BLUMENAU (SC)}

Badenfurt, por outro lado, possui maior (37\%), ruim (31\%) e péssima (15\%).

quantidade e porcentagem nas classes moderada

Tabela 02 - Resultados do IC para o bairro Centro e Badenfurt, Blumenau (SC).

\begin{tabular}{lcccc}
\hline \multicolumn{1}{c}{ IC } & $\begin{array}{c}\text { Centro } \\
\text { Número de trechos }\end{array}$ & $\mathbf{N}^{\circ}$ & $\mathbf{\%}$ & $\begin{array}{c}\text { Badenfurt } \\
\mathbf{N}^{\circ}\end{array}$ \\
\hline Ótima (6-10) & 134 & 68 & 11 & 17 \\
Moderada (4-5,9) & 52 & 27 & 24 & 37 \\
Ruim (2-3,9) & 7 & 4 & 20 & 31 \\
Inadequada (1-1,9) & 3 & 2 & 10 & 15 \\
\hline & 196 & 100 & 65 & 100 \\
\hline Extensão de trechos & $\mathbf{K m}$ & $\mathbf{\%}$ & $\mathbf{K m}$ & $\%$ \\
\hline Òtima (6-10) & 19,4 & 73,5 & 1,7 & 7,5 \\
Moderada (4-5,9) & 5,7 & 21,8 & 8,1 & 35,7 \\
Ruim (2-3,9) & 1,0 & 3,9 & 9,7 & 42,7 \\
Inadequada (1-1,9) & 0,2 & 0,8 & 3,2 & 14,1 \\
\hline Total & 26,3 & 100 & 22,9 & 100 \\
\hline
\end{tabular}

Em relação a extensão dos trechos, o Centro apresentou 19,4 km de trechos com IC entre 6 e 10, sendo um total de 73,5 \% em relação a extensão total. 0 Badenfurt, apresentou apenas $1,7 \mathrm{~km}$ ou 7,5 \% da mesma classe. Em relação a classe entre 4 e 5,9, o Centro apresentou 5,7 km ou $21,8 \%$ e o Badenfurt com $8,1 \mathrm{~km}$ de trechos ou $35,7 \%$. 0 Centro apresentou ainda $1,0 \mathrm{~km}$ ou $3,9 \%$ de trechos de IC entre 2 e 3,9 e o Badenfurt com uma extensão mais expressiva, 9,7 km ou 42,7\%. A situação "inadequada", no Centro apareceu em apenas 0,2 km de trechos ou 0,8 $\%$ dos trechos e o Badenfurt com 3,2 km ou $14,1 \%$. Essa informação foi em parte corroborada pelas fotos das calçadas por bairro obtidas durante o levantamento de campo (Figura 2). 


\section{ESPACIALIZAÇÃO DO ÍNDICE DE CAMINHABILIDADE (IC) COMO FERRAMENTA DE PLANEJAMENTO NA MOBILIDADE URBANA DOS BAIRROS CENTRO E BADENFURT EM BLUMENAU (SC)}
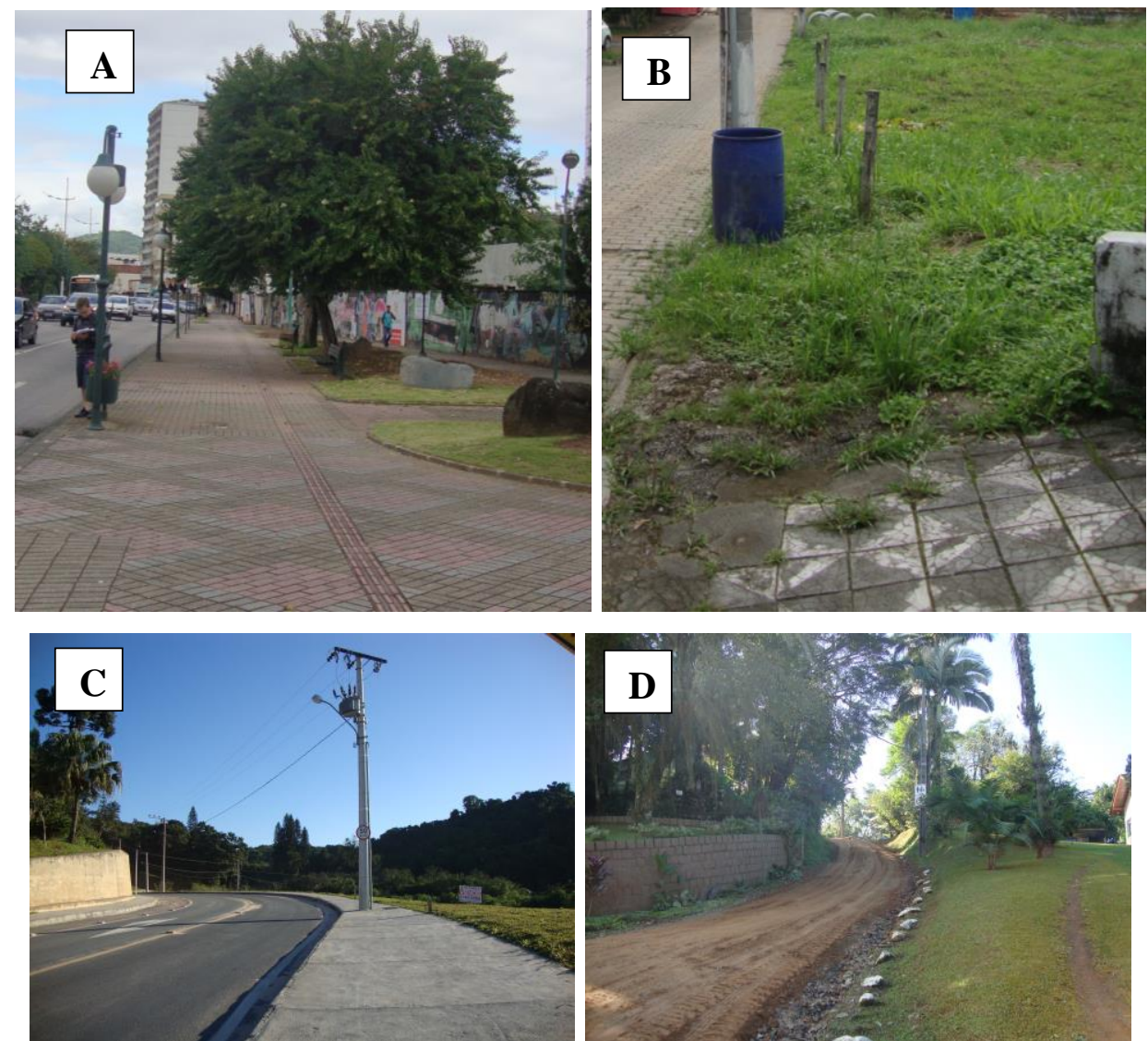

Figura 02 - (A) Melhorias e aperfeiçoamento - Centro; (B) intervenção a curto prazo - Centro; (C) intervenção imediata - Badenfurt e (D) situação crítica - Badenfurt - Blumenau (SC).

No Centro, as três variáveis que receberam melhor pontuação foram largura, obstáculos e nivelamento, e as com pior pontuação foram mobiliário urbano, proteção contra intempéries e iluminação. Para o Badenfurt, as variáveis que tiveram a melhor pontuação foram largura, nivelamento e proteção contra intempéries, e as com pior pontuação foram mobiliário urbano, travessia e obstáculos.

O resultado encontrado para o IC dos bairros sistematiza em dados quantitativos, e por meio de mapeamento georreferenciado representa o conhecimento empírico sobre a qualidade das calçadas dos bairros estudados. Ao percorrer os bairros é visível uma menor qualidade das calçadas no bairro Badenfurt que é menos populoso, tem características de periferia, ou seja, com pouca infraestrutura urbana, situa- se no limite do município e consequentemente tem menor prioridade de ação por parte do poder público. Contudo, o IC do Badenfurt teve uma ampliação, demonstrando um aumento de 2005 (IC = 1,8) para 2015 (IC = 3,9). Isto ocorreu, devido à implantação de novas calçadas, em função da construção de uma nova ponte de ligação entre a área Oeste e Norte do município de Blumenau, potencializando o desenvolvimento urbano do Badenfurt. Esse aumento do IC não foi evidenciado no bairro Centro, que apresentou inclusive uma redução de 7,1 em 2005, para 6,7 em 2015. Contudo, o Centro concentra uma densidade populacional mais elevada, os principais bens de serviços, o comércio e os equipamentos urbanos. 


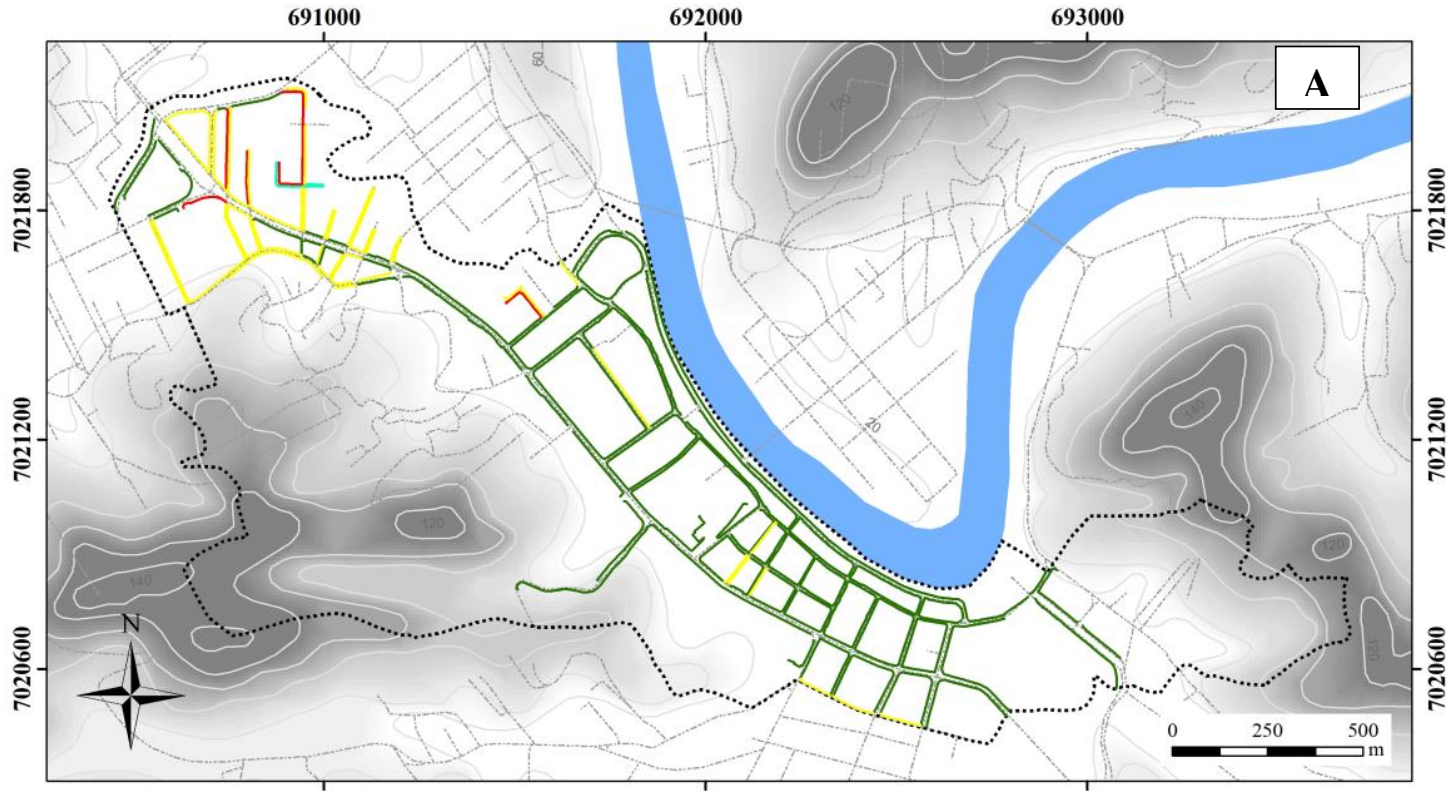

Legenda

Vias urbanas

Bairro Centro

3 Rio Itajaí-Açú Curvas de nível
Índice de Caminhabilidade (\%)

Número de trechos

- 0 - 1,9 (Inadequado) (2\%)

- 2 - 3,9 (Ruim)

$4-5,9$ (Moderado)

-6 - 10 (Ótimo)
$(4 \%)$

(27\%)

(68\%)

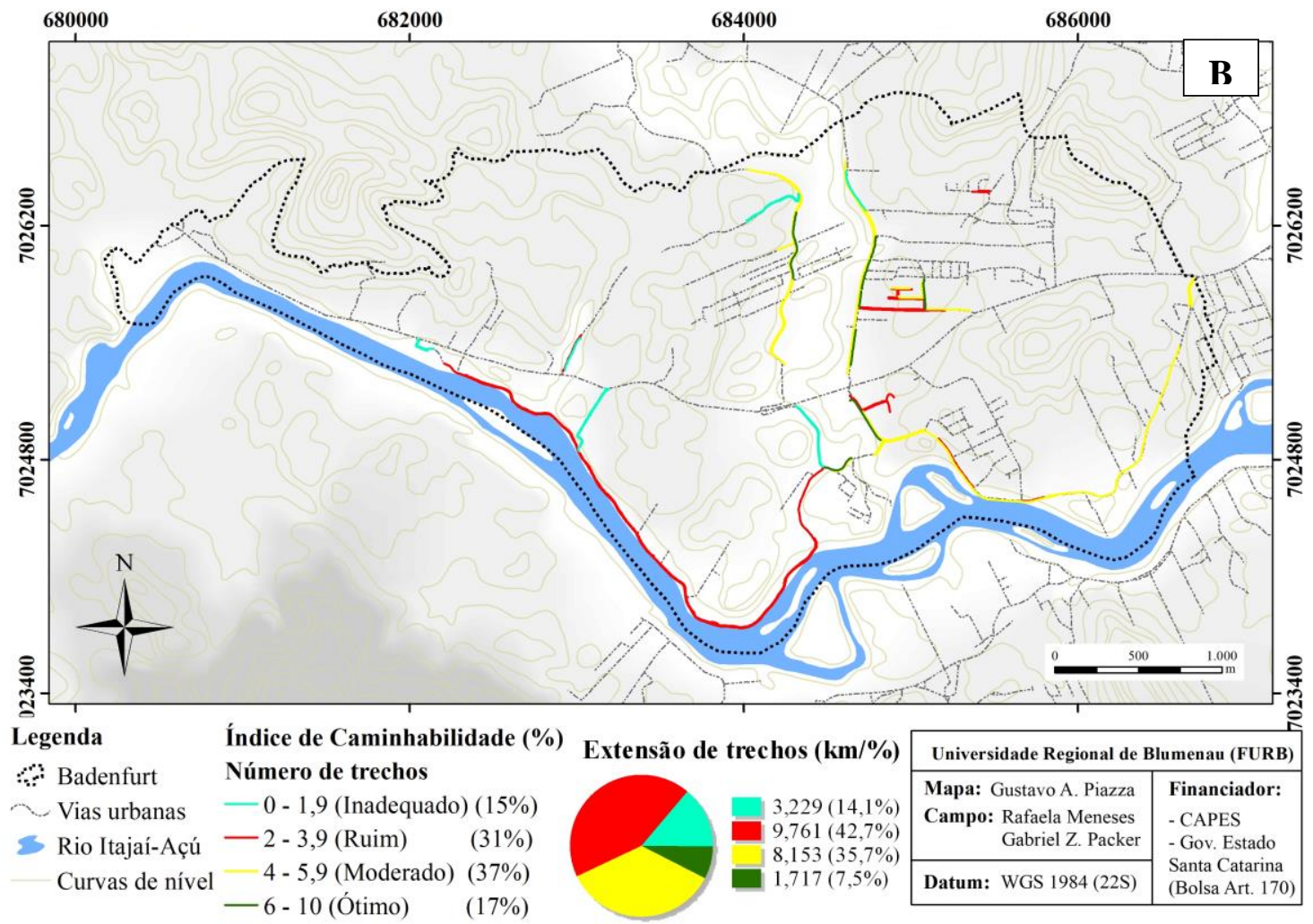

Figura 03 - Índice de Caminhabilidade (A) Centro e (B) Badenfurt - Blumenau. 


\section{ESPACIALIZAÇÃO DO ÍNDICE DE CAMINHABILIDADE (IC) COMO FERRAMENTA DE PLANEJAMENTO NA MOBILIDADE URBANA DOS BAIRROS CENTRO E BADENFURT EM BLUMENAU (SC)}

Especialmente no bairro Badenfurt, mas também no Centro, identificou-se que as calçadas apresentam problemas para a circulação das pessoas. Entende-se que o poder público é o responsável e deve investir na melhoria dessas calçadas, pois são espaços públicos, lugares de trocas e convívio social. Os resultados demonstram a necessidade de aplicação mais efetiva da Lei Federal no. 12.587 de 03/01/2012, que institui a Política Nacional de Mobilidade Urbana, na qual o sistema de mobilidade deve estar distribuído em toda a extensão municipal, priorizando-se os modos não-motorizados de transporte como o caminhar.

\section{CONCLUSÃO}

O SIG demonstrou ser uma ferramenta eficiente para espacializar e monitorar o índice de caminhabilidade (IC), tendo como estudo de caso os dois bairros no município de Blumenau, Badenfurt e Centro, em Santa Catarina. A vantagem do SIG foi a rapidez da atualização e disponibilização dos resultados. Muratori e Lobo (2015) também encontraram benefícios com a utilização do ambiente SIG no planejamento urbano, pois ele permite o acompanhamento das transformações urbanas.

O IC permite identificar as melhorias necessárias para ampliação da qualidade das calçadas. Com a adequação dos trechos de calçadas para os deslocamentos, o cidadão se sente motivado a utilizar os espaços públicos, bem como o transporte público coletivo, por exemplo, pois entende que terá um bom acesso para chegar até esses distintos modais (ônibus, metrô, trem, por exemplo). De forma geral, o IC foi superior no bairro central do município de Blumenau em relação ao bairro limítrofe do Badenfurt.

No Centro, deve-se melhorar o mobiliário urbano, a proteção contra intempéries e a iluminação pública, indicando-se melhorias e aperfeiçoamento das variáveis analisadas. Para o Badenfurt há necessidade de maior qualificação e implementação do mobiliário urbano, travessia acessível e remoção de obstáculos, devendo-se realizar uma intervenção imediata.

\section{REFERÊNCIAS}

BARTON, J., PRETTY, J. What is the Best Dose of Natureand Green Exercise for Improving Mental Health? A Multi-Study Analysis. Environ. Sci. Technol, v. 44, p. 3947-3955, 2010.

BLUMENAU. Processo de Revisão do Plano Diretor de Blumenau (PDB) 2005/2006 Relatório da Leitura da Cidade. Estado de Santa Catarina, Município de Blumenau, Secretaria Municipal de Planejamento Urbano - Diretoria de Planejamento Urbano. Outubro, 2005.

BRADSHAW, C. Creating - and using - a rating system for neighbourhood walkability: towards an agenda for "local heroes". Proceedings of the 14thInternational Pedestrian Conference, Ottawa, Canada. 1993.

BRASIL. Lei № 12.587, de 3 de janeiro de 2012, que institui as diretrizes da Política Nacional de Mobilidade Urbana. Brasília, DF. Disponível em: http://www.planalto.gov.br/ccivil_03/_ato20112014/2012/lei//12587.htm. Acesso em: setembro de 2015.

BUDAG, L. Vida coletiva e trocas sociais na área central de Blumenau/SC. Dissertação (Mestrado em Geografia). Florianópolis, SC, Universidade Federal de Santa Catarina. 2004.

BUDAG, L.; TRICÁRICO, L. Levantamento do Índice de Caminhabilidade de Itapema/SC. (Relatório de atividades). Universidade do Vale do Itajaí, Balneário Camboriú. 2009.

BUDAG, L.; VITORINO, A. Levantamento do Índice de Caminhabilidade de Itajaí/SC. (Relatório de Pesquisa/2005), Balneário Camboriú, SC, Universidade do Vale do Itajaí. 2005.

FRANK, B.; SEVEGNANI, L. (Org.). Desastre de 2008 no Vale do Itajaí: água, gente e política. Blumenau: Agência de Água do. Vale do Itajaí, 2009, p. 138-147.

GHIDINI, R. A caminhabilidade: medida urbana sustentável. Revista dos Transportes Públicos ANTP. São Paulo, ano 33, p. 21-33, jan/abr., 2011. IBGE - INSTITUTO BRASILEIRO DE GEOGRAFIA E ESTATÍSTICA. IBGE: Cidades - Blumenau. Censo 


\section{ESPACIALIZAÇÃO DO ÍNDICE DE CAMINHABILIDADE (IC) COMO FERRAMENTA DE PLANEJAMENTO NA MOBILIDADE URBANA DOS BAIRROS CENTRO E BADENFURT EM BLUMENAU (SC)}

demográfico. Disponível em: http://www.ibge.gov.br

http://cidades.ibge.gov.br/xtras/perfil.php?codm un=420240. Acesso em: setembro de 2015.

MURATORI, A.M.; LOBO, M.L.C. Aptidão urbana aos instrumentos do estatuto da cidade: perspectivas metodológicas. Ra'e GA - O Espaço Geográfico em Análise, Curitiba, v. 34, p.26-49, Ago/2015.

SANTOS, E.C. dos. (2003). Seminário paranaense sobre calçadas. Curitiba: ABCP.

SIEBERT, C., LORENZINI, L. Caminhabilidade: uma proposta de aferição científica. Dynamis Revista Tecno-científica, 6 (23), p. 89-106. 1998.

SILVA, J.X., ZAIDAN, R.T. Geoprocessamento e análise ambiental: aplicações. Rio de Janeiro: Bertrand Brasil, 2004.

STEINER, A. Reflexiones. Nuestro Planeta - la revista del Programa de las Naciones Unidas para el Medio Ambiente (PNUMA), 5, 2009. Disponível em:<http://www.unep.org/pdf/OP_sept/SP/OP2009-09-sp-ULLVERSION.pdf.> Acessado em 20 abr. 2013.

SZEREMETA, B.; ZANNIN, P.H.T. a importância dos parques urbanos e áreas verdes na promoção da qualidade de vida em cidades Ra'e GA - O Espaço Geográfico em Análise, Curitiba, v.29, p.177-193, dez/2013.

$\mathrm{RECH}$, J. V. Desenvolvimento e Teste de um Método de Análise de Acessibilidade a Serviços públicos de Saúde, num Contexto de Demanda Variável. Tese Doutorado. UFSC, Florianópolis, Santa Catarina, Brasil. 2004.
ROCHA, P. G. O.; XIMENES, T. C. F.; GUERRA, S. M. S. Geoprocessamento aplicado a seleção de áreas para implantação de aterro sanitário: estudo de caso, consórcio Brejo Madre de Deus e JuatubaPE. Revista GEAMA, Recife, v.2, n.1, p. 79-89, setembro - 2015.

RUTZ, N.; MERINO, E.; PRADO, F.H.do. Determinação do Índice de Caminhabilidade Urbana. In: 16․ Congresso Brasileiro de Transporte e Trânsito, 2007, Maceio. Anais... Maceio: ANTP. p.1-10, 2007.

VIEIRA, R.; MORASTONI, R. Qualidade das calçadas na cidade de Camboriú/SC: em busca da acessibilidade e mobilidade sustentável para área turística. Revista Brasileira de Pesquisa em Turismo, 7(2), p. 239-259, 2013.

VIEIRA, R.; PACKER, G.Z.; MENESES, R.N. Índice de caminhabilidade de Blumenau em Santa Catarina/Brasil: uma análise do Centro e do bairro Badenfurt. In: VIII Seminário Internacional de Investigaciòn en Urbanismo, 2016, Balneário Camboriú. Anais... Balneário Camboriú: UNIVALI, 2016. p. 1-15.

VIEIRA, R.; PEREIRA, L.N.; MUSSI, C.S. Análise da caminhabilidade em cidades turísticas através de Sistemas de Informações Geográficas (SIG): um estudo de caso no litoral centro-norte de Santa Catarina, Brasil. In: Tourism \& Management Studies, 2014, Algarve. Anais...Algarve: Portugal. p.101-115 